\title{
DESCRIÇÃo de LínguAs Indígenas EM Gramáticas Missionárias do Brasil Colonial*
}

\author{
(Description of Indian Languages in Missionary Grammars \\ of the Colonial Period in Brazil)
}

\author{
Ronaldo de Oliveira BAtISTA \\ (Universidade Presbiteriana Mackenzie; CEDOCH/DL-USP)
}

\begin{abstract}
In the 16th and 17th centuries, Jesuits wrote two of the Indian language grammar spoken in Brazil in the colonial period. José de Anchieta and Luiz Figueira described the ancient Tupi in 1595 and in about 1621 respectively, and Luiz Vincencio Mamiani the Quiriri Indian Language in 1699. This production aimed at facilitating, through language learning, the contact between Indians and Jesuits and consequently their colonization and catechization. Some methods and practices of Jesuits language description will be analyzed in this paper. To do so, we will follow linguistic historiography methodologies (Koerner 1989, 1996 and Swiggers 1979, 1983) concerning material selection, description and analysis, trying to characterize what we call missionary linguistics in the Brazilian tradition. The analysis of these three pieces of work will show a grammar production form, common to these three authors and its insertion in the wide grammar tradition of the period, later called missionary linguistics. One of its most important characteristics is its relation to what, conventionally, is called in linguistic bistory, the Traditional Grammar.
\end{abstract}

KEY-WORDS: linguistic historiography; Brazil; jesuits; grammars.

Resumo: Nos séculos XVI e XVII, jesuitas escreveram gramáticas de duas das línguas indígenas faladas no Brasil colonial: José de Anchieta e Luís Figueira descreveram o tupi antigo em 1595 e ca. 1621 respectivamente; Luís Vincencio Mamiani, a língua indígena quirivi em 1699. Essa produção teve como objetivo facilitar, por meio da aprendizagem das línguas, o contato entre jesuítas e indígenas, tendo em vista a colonização e a catequização. Neste trabalho, são analisados alguns dos métodos e práticas de descrição das línguas pelos jesuítas. Para isso, seguem-se as indicações metodológicas da

* Agradeço as observações feitas pelos pareceristas em relação a uma primeira versão deste texto. 
bistoriografia lingüística (Koerner 1989, 1996 e Swiggers 1979, 1981, 1983) em relação à seleção, descrição e análise do material, procurando caracterizar o que chamamos de tradição brasileira da lingüística missionária. O exame das obras nos mostrará uma forma de produção gramatical comum aos três autores e a sua inserção numa tradição posteriormente chamada de lingüística missionária, que teve como uma de suas características mais destacadas a relação com o que se convencionou nomear na história da lingüística de Gramática Tradicional.

PaLAVRAs-CHAVE: historiografia lingüística; Brasil; jesuitas; gramáticas.

\section{Introdução}

Em 1500, navegadores liderados por Cabral, em nome da Coroa portuguesa, chegaram às terras que viriam a ser chamadas de Brasil ${ }^{1}$. A partir de 1530 teve início a colonização do território brasileiro, que seria descrito ao mesmo tempo com ares de Paraíso e Inferno terrestres, com seus nativos considerados bárbaros e necessitados de redenção pela conversão à fé católica. Em 1549 missionários da Companhia de Jesus chegaram ao Brasil, selando uma das parcerias mais sólidas e importantes da nossa história colonial.

Em meio a fatores socioeconômicos característicos do processo de colonização, uma necessidade se impunha: a expansão da fé católica, com o objetivo de garantir não só o espaço para a Igreja, mas também uma unidade religiosa que fortaleceria Portugal.

Os jesuítas, assim, dedicaram-se à conversão dos indígenas e, com esse intuito, deram um passo importante na história dos estudos sobre línguas e linguagem. Esses missionários (em consonância com o que outros missionários faziam ao redor do mundo) aprenderam algumas das línguas

\footnotetext{
1 A questão da denominação das terras descobertas que constituiriam o território brasileiro é complexa e objeto de muitos estudos na historiografia. Sugerimos, para uma introdução à questão, a leitura do texto de Souza 2004. Neste trabalho, assumimos a denominação Brasil (ainda que não se possa falar de uma unidade administrativa, política, tal como reconhecemos em períodos posteriores à Colônia), já que no período colonial esta denominação foi utilizada, por exemplo, pelos padres José de Anchieta e Manuel da Nóbrega. Não pretendemos com essa posição dar a idéia de que na época o Brasil era semelhante ao território que hoje conhecemos. No período, Pará e Maranhão podem ou não ser considerados como parte do Brasil, dependendo dos momentos em que se faz referência ao território colonial.
} 
indígenas ${ }^{2}$ utilizadas no território colonial, promovendo a gramatização ${ }^{3}$, isto é, a produção de artes de gramática ${ }^{4}$, de duas línguas indígenas (tupi antigo ${ }^{5}$ e quiriri) faladas no Brasil colonial nos séculos XVI e XVII. Dessa maneira, os jesuítas estavam inseridos em um processo no qual línguas das Américas, da África e da Ásia foram aprendidas num momento que ficou conhecido, posteriormente, como de expressiva publicação de obras referentes às línguas das terras colonizadas por nações européias a partir das Grandes Navegações (cf. Hovdhaugen 1996).

Assim, duas línguas indígenas brasileiras - tupi antigo e quiriri foram colocadas pelos jesuítas em regras, como dizia a metalinguagem da época. Essa produção gramatical ocorreu no Brasil pelas mãos de José de Anchieta (1534-1597), Luís Figueira (1573-1643) e Luís Vincencio Mamiani (1652-1730). Como resultado desse processo, publicaram-se:

- a Arte de gramática da língua mais usada na costa do Brasil, de José de Anchieta, em 1595;

- a Arte da Língua Brasílica, de Luís Figueira, em ca. 1621;

- a Arte de Gramática da Língua Brasílica da Nação Kiriri, de Luís Vincencio Mamiani, em 1699.

Neste trabalho, analisaremos essa produção gramatical, procurando estabelecer as características de uma tradição lingüística missionária jesuítica brasileira. Para tanto, focalizaremos nossa atenção num trabalho de caráter lingüístico, em que procuraremos descrever e analisar alguns dos procedimentos e estratégias utilizados pelos jesuítas na descrição gramatical do tupi antigo e do quiriri. A nossa análise será norteada pelas indicações metodológicas da historiografia lingüística, tal como proposta por autores como Koerner (1989, 1996) e Swiggers (1979).

\footnotetext{
2 Nesse processo de aprendizagem de línguas e de produção de gramáticas também está inserida a obra do jesuíta Pedro Dias (1621-1700) para a língua africana quimbundo: Arte de gramática da língua de Angola, publicada em 1697. Essa publicação ocorreu tendo em vista o contato com a população escrava no território brasileiro.

3 Termo cunhado por Auroux (1992) indicando a produção de gramáticas, dicionários, listas de palavras, ocorrida principalmente a partir do Renascimento europeu, estimulada pela descoberta de novas línguas em decorrência dos descobrimentos e também pela autonomia e expansão políticas das recentes nações européias.

4 Denominação corrente na época para obras que deveriam seguir critérios como brevidade na exposição de aspectos fundamentais das estruturas gramaticais das línguas.

5 Também chamado de Tupinambá.
} 


\section{A lingüística missionária jesuítica}

A postura lingüística adotada no Brasil visava ao domínio da língua dos índios pelos jesuítas. Era necessário que o religioso conhecesse a língua para realizar missas que pudessem ser compreendidas pelos nativos e também para efetivar a confissão ${ }^{6}$.

Como resultado dessa política lingüística, houve a produção de catecismos, gramáticas, vocabulários, listas de palavras e dicionários. Um material escrito para servir de subsídio para o ideal de conversão dos nativos para a fé cristã. Pode-se apontar, pelo menos em tese, que essa produção lingüística missionária não existiu por ela mesma, pelo interesse dos jesuítas com as línguas descobertas (cf. Hovdhaugen 1996). É uma produção, antes de qualquer coisa, instrumental ${ }^{7}$.

Essa função instrumental determinou uma das características da lingüística missionária dos séculos XVI e XVII: o uso do conhecimento da descrição gramatical do latim para realizar as descrições das línguas indígenas. As gramáticas missionárias foram escritas a partir do que era conhecido como os métodos de descrição lingüística utilizados nas gramáticas clássicas da tradição greco-latina e na produção gramatical renascentista para o latim e os vernáculos europeus ${ }^{8}$.

A Gramática Tradicional foi utilizada como base para a descrição das línguas. A historiografia lingüística reconhece a expressão "gramática tradicional" como equivalente ao conjunto de proposições descritivas e metalingüísticas de origem greco-latina em seu período conhecido como Antiguidade clássica ocidental. Dessa maneira, quando falarmos da utilização de um modelo latino, estaremos nos referindo a formas de descrição da língua utilizadas em gramáticas da tradição greco-latina ocidental e

\footnotetext{
6 Num primeiro momento, as missas foram realizadas em latim. Ao longo do processo de catequização, tal opção não se revelou como a mais adequada.

Alguns autores, em relação ao material produzido pelos jesuítas para o tupi antigo, não compartilham a idéia do caráter instrumental das gramáticas. Rodrigues (1997) é um dos autores que, em vez da opção por uma caracterização instrumental, insiste no valor descritivo dessas gramáticas. 8 Ainda que Koerner afirme que as gramáticas vernaculares não influenciaram na lingüística missionária, porque ou não receberam a devida atenção, de fato serão obras que apenas séculos após os XVI e XVII terão reconhecida sua contribuição, ou porque, ao também repetirem modelos latinos, reforçaram a idéia da adequação das categorias latinas a outras línguas, pelo menos como estratégia didática (Koerner 1992).
} 
também em algumas gramáticas do Renascimento que se caracterizaram por dar continuidade ao modelo clássico (cf. Law 2003: 13-93; Swiggers 1997: 69-131). No contexto educacional e de formação intelectual jesuítico, os missionários seguiram obras como as de Donato ( $4^{\circ}$. séc. a.C.) e de Manuel Álvares (1526-1583), para pôr em prática a descrição das línguas indígenas. Uma exceção talvez seja Anchieta, que, segundo alguns autores, teria se mantido, em passagens de sua gramática, distante do uso de uma forma de descrição lingüística tal como empregada nessas gramáticas de origem greco-latina? .

Nesse processo de transferência de conhecimentos gramaticais próprios à descrição do latim para a descrição de línguas indígenas, podem ser percebidos aspectos como: a busca de equivalências entre categorias gramaticais latinas e categorias das línguas indígenas; a utilização de um quadro descritivo das classes de palavras das línguas indígenas a partir das partes do discurso divididas tal como no latim e/ou no grego; e a manutenção da metalinguagem. Se esse procedimento pode causar estranheza, quando pensamos em diferenças tipológicas entre latim e línguas exóticas, foi ele um dos responsáveis pela manutenção do instrumental de descrição gramatical greco-latino, propiciando o reconhecimento de uma tradição gramatical de aspecto cumulativo, permitindo que muitas línguas pudessem ser aprendidas pelo modelo de descrição gramatical do latim (cf. Auroux 1992: 78).

Em algumas passagens das descrições realizadas pelos jesuítas para o tupi antigo e o quiriri, no entanto, não se observou uma mera transferência do instrumental descritivo utilizado para a descrição do latim, por causa de aspectos particulares das línguas indígenas. Entre esses aspectos podem ser citadas a incorporação nominal e verbal, a topicalização de adjuntos e a expressão do tempo nos nomes ${ }^{10}$. Essa constatação possibilita nuançar a presença de métodos descritivos próprios à língua latina, já que, mesmo seguindo uma espécie de guia a partir da metalinguagem e formas de descrição do latim, os jesuítas em alguns momentos souberam abrir mão do referencial conhecido, possibilitando, assim, o registro de características

\footnotetext{
9 Rodrigues 1995 e 1997 manifesta ponto de vista em que realça uma independência de Anchieta em relação ao que se conhecia de descrição lingüística por meio de obras gramaticais do latim.

10 Rodrigues 1997 aponta exemplos desses aspectos.
} 
gramaticais particulares das línguas indígenas. São por posicionamentos como esses que as artes de gramática se mostrariam importantes para os trabalhos da lingüística indígena, principalmente em sua feição histórica, já que possibilitaram uma reconstrução mais apropriada de aspectos gramaticais das línguas.

Se esse método de descrição de línguas no Renascimento contribuiu, sem dúvida, para a caracterização da história das gramáticas ocidentais como uma história de saber cumulativo ${ }^{11}$, contribuiu também para 0 início de uma tradição conhecida como gramática contrastiva (Auroux 1992: 79), na qual dados de línguas poderiam ser comparados, ressaltando semelhanças e diferenças.

\section{As artes de gramática do Brasil colonial}

As gramáticas de Anchieta, Figueira e Mamiani foram intituladas de artes de gramática, nomeação corrente na época, caracterizando uma descrição breve de estruturas gramaticais de uma língua, com objetivo pedagógico. As artes tinham seu método de descrição pautado no instrumental descritivo próprio para a língua latina e deviam obedecer aos princípios de brevidade e economia, tendo em vista a aprendizagem das línguas pelos missionários no menor período de tempo possível, uma vez que era necessário acelerar a catequização e melhorar a comunicação entre colonizadores, religiosos e nativos.

Essas gramáticas tinham motivação pedagógica e não o ideal de preservação de uma língua ou a afirmação de uma nacionalidade e não podem ser dissociadas da idéia de transmissão pedagógica (Altman 1997: 156).

Era esperado que os jesuítas que utilizassem as gramáticas tivessem conhecimento da descrição gramatical do latim, como enfatizava Anchieta em uma carta de 1555, ao dizer que a arte não teria proveito para os que não soubessem gramática, que se entendia como gramática latina:

11 "A história da gramatização convida a não abandonar totalmente uma concepção cumulativa e progressiva em matéria de história das ciências, em proveito de uma concepção puramente descontinuísta. [...]. ... a gramatização das línguas do mundo não teria nenhuma chance de ser finalizada um dia se fosse necessário fazer tábua rasa em cada mudança de moda ou de teoria." (Auroux 1992:83) 
Quanto à língua, eu estou nela algum tanto adiante, ainda que é muito pouco para o que se soubera, se me não ocuparam em ensinar gramática. Todavia tenho toda a maneira dela por arte, e para mim tenho entendido quase todo o modo dela. Não a ponho em arte, porque não há quem a aproveite. Somente aproveito-me eu dela, e aproveitar-se-ão os que de lá vierem, que souberem gramática. (Anchieta 1984: 86, grifo meu)

As artes apresentavam uma estrutura semelhante:

a) tratamento da parte sonora da língua, ortografia e acento;

b) descrição das partes do discurso (chamadas de partes da oração) e da estrutura das palavras das línguas (acidentes da palavra, compostos e derivados);

c) um reduzido tratamento da parte sintática.

As artes jesuíticas brasileiras ${ }^{12}$ tiveram (à exceção, talvez, de Anchieta, nas primeiras redações de sua arte ${ }^{13}$ ) como um dos modelos a obra de Manuel Álvares, Institutione Grammatica ${ }^{14}$, publicada pela primeira vez em 1572. Essa gramática do latim alcançou grande sucesso na época, sendo comentada por vários autores e indicada como o manual de aprendizagem do latim pelo programa de estudos dos jesuítas conhecido como Ratio Studiorum (divulgado em sua versão definitiva em 1599).

\footnotetext{
12 As gramáticas escritas pelos jesuítas para serem utilizadas no território brasileiro não foram impressas no Brasil, que conheceria uma imprensa apenas no século XIX, com a chegada da família real portuguesa.

13 Ver o trabalho de Navarro 1995 a esse respeito.

14 Manuel Álvares, gramático português, jesuíta. Ensinou língua e literatura latinas em Lisboa e Coimbra. Sua gramática latina, de título original Emmanuelis Alvari, e Societate Jesu, De Institutione Grammatica Libri Tres, integri, ut ab auctore sunt editi, nunc emendatius excusi, foi publicada em 1572, em Lisboa por João da Barreira, e ficou mais conhecida como Institutione Grammatica. A obra está dividida em três livros: etimologia, sintaxe e prosódia, e seu objetivo era fornecer uma base para os estudos de latim nos colégios jesuítas. A presença da gramática de Álvares foi muito intensa no ambiente jesuítico (substituindo a obra de Despautério - Comentarii gramatici (1506-1519) -, utilizada anteriormente), sendo a obra expressamente indicada para a aprendizagem do latim, e serviu de modelo para artes de gramática de línguas exóticas.
} 


\section{Os procedimentos e as estratégias de descrição nas artes das línguas indígenas}

As gramáticas missionárias jesuíticas brasileiras utilizaram uma espécie de método comparativo que procurava buscar equivalências entre as línguas descritas e línguas de maior conhecimento por parte dos missionários, como o português, o latim e mesmo o castelhano.

O que chamamos de busca de equivalências é uma transferência funcional da metalinguagem definidora de categorias gramaticais latinas que pudessem apresentar semelhanças com categorias das línguas em descrição, semelhanças estas estabelecidas em relação às funções gramaticais desempenhadas. Destaca-se nesse procedimento a manutenção da metalinguagem utilizada nas gramáticas latinas, que também surge com algumas modificações ou ajustes.

Essa estratégia associava-se ao ideal de transmissão pedagógica. Apontando semelhanças e diferenças, o processo de ensino/aprendizagem tornava-se menos complicado, uma vez que diferentes realidades lingüísticas passavam a ser percebidas como semelhanças e diferenças, bem de acordo com o espírito da época, que buscava na similitude a compreensão do mundo.

O momento histórico, em conseqüência das Grandes Navegações, reconhecia e interpretava o diferente pelo olhar comparativo. Essa atitude diante do mundo transfere-se para o campo lingüístico, no qual as línguas até então desconhecidas passaram a ser encaradas a partir do ponto de vista comparativo. Os comentários dos viajantes e colonizadores ressaltavam a falta ou as diferenças em relação aos costumes de nativos das terras americanas, africanas e asiáticas em contraste com os costumes europeus, assim como os gramáticos ressaltavam a falta de sons e as diferenças nos sistemas que descreviam.

Nesta lingoa do Braril não ha f. l. s. z. rr. dobrado nem muta com liquida, vt cra, pra, \&c. Em lugar do s.in principio, ou medio dictionis rerue, ç. com zeura, vt

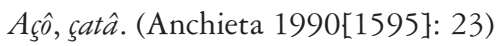

Os procedimentos descritivos de línguas pareciam encontrar paralelo com a visão de mundo da época. Os europeus que descobriam o diferente procuraram captar o que lhes era diverso por meio de um filtro que ressaltava a busca de equivalências. 
O fato de serem as gramáticas jesuíticas associadas à transmissão didática gerou o uso de um procedimento que descrevia a combinação de unidades, as transformações morfofonológicas, a associação de palavras nas orações, tudo descrito por uma espécie de explicação passo-a-passo do que ocorria com a língua quando em uso, como no exemplo de Anchieta a seguir.

Tambẽ algũs verbos re hão de dercreuer com dous, ij, hum confoante, outro vogal depois do artigo \& não com, gi, vt aijquî, ajbo ${ }^{\wedge}$. Porque tendo o accuratiuo exprerro, ou, o reciproco, \& outras partes, (vt infra latius) perdem o primeiro, i. vt pirá ibómo, peixe frechando: \& re re ercreuera cõ, gi ouuera de dizer, piragibómo. (Anchieta 1990[1595]:33)

A partir desses procedimentos e estratégias, os gramáticos se valeram de alguns critérios para suas delimitações das unidades. No plano sonoro foi utilizado com mais produtividade o critério auditivo (ou perceptivo). $\mathrm{O}$ gramático descrevia as unidades sonoras das línguas, e suas possíveis alterações, a partir do que ouvia, sem maiores auxílios de uma abordagem articulatória. Quanto às delimitações das palavras e suas classificações, partes da oração, e combinação em unidades maiores, os gramáticos utilizaram, principalmente, critérios morfológicos (a palavra como unidade fundamental), funcionais (como os itens em descrição se relacionavam com outras unidades da língua) e semânticos (com uma relação entre elementos lingüísticos e elementos não-lingüísticos).

Esses critérios valorizaram a abordagem feita a partir das unidades mais elementares (letras), partindo para sua constituição como palavra (unidade fundamental da gramática) e chegando à combinação em segmentos maiores como a oração, entendida como a combinação de palavras que expressava um significado completo.

A seguir, mostramos e analisamos a utilização dos procedimentos e estratégias de descrição nas gramáticas escritas para o Brasil colonial dos séculos XVI e XVII.

A indicação e a análise desses procedimentos e estratégias, em relação ao nosso corpus, é tarefa do historiógrafo e surge a partir de seu ponto de vista, uma vez que os jesuítas não explicitaram ou indicaram, de forma ampla e intencional, quais métodos ou princípios seguiram para descrever o tupi antigo e o quiriri. No entanto, essa é uma tarefa importante a ser 
executada no campo da historiografia lingüística, como ressalta Swiggers (1997: 111), considerando que as gramáticas missionárias caracterizam-se pela ausência de informações sobre os procedimentos de análise, ainda que esparsos comentários sobre eles possam ser detectados em meio a descrições lingüísticas.

Em relação a esse ponto, o jesuíta Mamiani tem um papel de destaque, já que, em algumas passagens de sua gramática, ele nos indica algo de seu procedimento de descrição ou então nos fornece alguma informação a respeito de como deveria ser a aprendizagem do quiriri. Nem Anchieta nem Figueira apresentaram comentários parecidos com os de Mamiani.

No exemplo abaixo, o gramático do quiriri justifica sua opção em adotar metalinguagem baseada nas descrições do latim e do grego e também nos informa sobre seu método descritivo.

Chamo Declinações, não porque sejão declinações dos casos nos nomes, ou de tempos, \& modos nos verbos, mas porque são quasi declinações dos pronomes, ou possessivos, ou substantivos, compostos com os mesmos nomes, \& verbos pelas tres pessoas em ambos os numeros, singular, \& plural: \& pela mesma razão, \& por ser regra gèral que abraça tãbem os verbos, se poem juntas as declinações dos nomes com as dos verbos. (Mamiani 1877[1699]:10)

\subsection{Letras, sons, vozes: as unidades sonoras das linguas}

Descreveu-se, de maneira geral, o som a partir de comparações com línguas como português e latim. Os critérios de análise das unidades sonoras foram o auditivo e o articulatório, com amplo uso do primeiro - o gramático descrevia e registrava as unidades sonoras conforme as ouvia, sem fornecer muitos detalhes do processo de produção dos sons, com abordagens a partir da produção articulatória ${ }^{15}$.

A descrição da parte sonora da língua nas gramáticas do tupi antigo e do quiriri é semelhante, evidenciando não só uma espécie de método comum à produção missionária dos séculos XVI e XVII (não apenas jesuítica, cf. trabalhos de Altman 1997, 2000), mas também destacando uma

15 Podemos relacionar a escassez de abordagens articulatórias não só ao prolongamento da tradição de descrição da Antiguidade clássica ocidental, mas também ao fato de que abordagens articulatórias pediam maior conhecimento da medicina, dessa maneira, é preciso lembrar que amplos e acurados estudos da anatomia humana não eram permitidos no âmbito da educação jesuítica. 
prática recorrente na produção gramatical do período, pelo menos nas descrições das línguas européias ocidentais e naquelas efetuadas pelos europeus do Ocidente (cf. Auroux 1992: 65-93 e Swiggers 1997: 133-206).

A produção gramatical renascentista não acrescentou novidades aos procedimentos de descrição das unidades sonoras da língua (parte dos estudos gramaticais que podemos chamar, nos termos atuais, de fonética/ fonologia, com a ressalva de que se encontra, nas gramáticas aqui estudadas, muito mais uma fonética instrumental, como lembra Auroux 1992: 65). O que se observa é a manutenção de procedimentos de descrição e análise já presentes na Antiguidade clássica ocidental (como a descrição de unidades sonoras a partir de um alfabeto, de um registro escrito, método presente nos gregos).

Ao examinar as gramáticas escritas pelos jesuítas para o contexto brasileiro, o que primeiro chama a atenção é o número reduzido de páginas dedicado ao estudo da parte sonora da língua, também uma característica da produção renascentista (que herdou esse aspecto da tradição clássica ocidental e da Idade Média, as quais também não se dedicaram com destaque ao estudo da parte sonora ${ }^{16}$ ), como pontua Swiggers (1997:111), ao lembrar a presença eventual, nas gramáticas do Renascimento, de partes dedicadas ao estudo dos elementos e arranjos sonoros das línguas.

Anchieta diferencia-se de Figueira e Mamiani em relação a esse aspecto. Ele descreve as unidades sonoras da língua de maneira diversa da dos outros gramáticos ao tratar não apenas do elenco das unidades sonoras, mas também de uma série de processos morfofonológicos do tupi antigo (como a combinação de afixos em radicais, ocasionando alterações nas unidades e na pronúncia), os quais deveriam ser observados pelos jesuítas para a utilização adequada da língua.

A gramática anchietana também não oferece de forma sistemática a apresentação das LETRAs (unidades sonoras e grafemas) do tupi antigo (como faz Figueira e também Mamiani para o quiriri), seguindo uma ordenação dos elementos no esquema alfabético, com a descrição da percepção

\footnotetext{
16 "Talvez tenha havido, desde a Antigüidade, em relação à fonética pura, um sentimento comparável ao que exprime Molière no Bourgeois gentilhomme: uma coisa muito bonita, mas para que serve?" (Desbordes 1995:100). "In general there was little interest in phonetics in the medieval period." (Kemp 1995:373)
} 
auditiva das unidades e explicação da produção (quando necessária). A descrição de Anchieta das unidades do sistema sonoro não é em forma de alfabeto e se destaca pelo tratamento dos fenômenos morfofonológicos, descrevendo alterações sonoras ocasionadas pelo AJUNTAMENTO (combinações) de unidades ou pelo acréscimo de parTículas (morfemas gramaticais que podiam ser prefixados ou sufixados a uma base lexical). Para tanto, Anchieta utilizou uma estratégia de descrição que procurava indicar o que ocorria com as unidades quando em uso.

Nas confoantes, c. g. cõmumente todos pronuncião de hũa merma maneira interporito i. vt Acepiâc, Acepiâcine, Aimeéng, Aimeénginé ...

(Anchieta 1990[1595]: 24)

R. mudare em, n. onde præceder til. m. ou, n. in vltima ryllaba, vt in futuro conjunctiui $[=$ subjuntivo $]$, nupa $\widehat{ }{ }^{\wedge}$, nupãneme, pro nupãreme, irumõ, irumôneme ... (id.: 28)

Em "Da Orthographia ou da Pronunciação", capítulo referente aos metaplasmos e sua pronúncia, Anchieta continua tratando dos processos morfofonológicos. Pode-se dizer que a parte da gramática dedicada ao estudo das unidades sonoras da língua realiza, na verdade, uma descrição desses processos, bastante produtivos no tupi antigo. Figueira conscientemente não tratou desses aspectos da língua: "Na composição de syllabas há muitas mudanças, que aqui não pomos, por evitar confusão: o uso basta" (Figueira 1621: fl.2).

A diferença de procedimento descritivo em Anchieta está, provavelmente, relacionada à diferente formação intelectual que ele teve, em relação aos outros gramáticos que aqui examinamos ${ }^{17}$. Anchieta não se formou, como Figueira e Mamiani, sob a influência do programa de estudos Ratio Studiorum e pode não ter seguido, estritamente, como modelo de descrição gramatical a obra de Manuel Álvares, que, de certa maneira, guiava a descrição dos jesuítas formados pelo programa Ratio Studiorum $^{18}$.

17 Navarro 1995 aborda extensivamente a formação intelectual de Anchieta, e é com base nessa leitura que fazemos essas afirmações.

18 Rosa 1997 destaca em Manuel Álvares esse papel de guia de descrição gramatical, e em texto de 1995 aponta diferenças entre os trabalhos de Anchieta e Figueira. 
Manuel Álvares, na sua Institutio Grammatica (1572), no capítulo I do livro terceiro, expõe as unidades sonoras, divididas em vogais e consoantes, e sílabas do latim, com a explicação da produção/percepção de algumas unidades (como [f], [s], [h], [i], [j], [u], [m], [n]), em um esquema de descrição que segue a estrutura alfabética, por assim dizer. É este esquema o adotado por Figueira e Mamiani.

A descrição das unidades relevantes a cada língua ocorreu tendo em vista os alfabetos latino e português, numa busca de equivalências entre as línguas indígenas e uma outra língua mais conhecida pelo missionário, sendo que esse procedimento ressaltava as unidades que não faziam parte das línguas que estavam sendo descritas, mas que figuravam como sons, unidades distintivas, em línguas européias de maior prestígio.

Nesta lingoa do Braril não há f. 1. s. z. rr. dobrado nem muta com liquida ${ }^{19}$. vt cra, pra, \&c. Em lugar do s. in principio, ou médio dictionis rerue, ç. com zeura, vt Açô, çatâ. (Anchieta 1990[1595]:23)

As letras de que re vra nerta língua, rão as reguintes. A, B, C, D, E, G, H, I, Y, K, M, N, O, P, Q, R, T, V, X, til. Ficão excluídas, F, L, S, Z. Tambem re não vfa rr dobrado ou arpero. (Figueira 1621:fl.1)

Entre as letras usadas nesta língua são as seguintes: A, æ, B, C, D, E, G, H, I, Y, K, M, N, O, P, R, S, T, V, W, Z, til. (Mamiani 1877[1699]:1)

Altman (2000: 8) aponta, com base no exame de gramáticas de línguas gerais sul-americanas dos séculos XVI e XVII, que a descrição das unidades sonoras ressaltando LETRAS ausentes nas línguas era procedimento comum de descrição, sendo que este traço também pode ser visto, explicitamente proposto, no primeiro gramático da língua castelhana, Antonio de Nebrija (1444-1522):

... aquel que quiere reduzir en artifício algun lenguage, primero es menester que sepa de si de aquellas letras que están en uso sobran algunas e si, por el contrario, faltan otras. (Nebrija 1946[1492]: 18)

19 Muta = oclusivas; líquida $=[1, \mathrm{r}]$, termo advindo do grego, origem incerta. Robins (1979:26) indica que "líquido" é termo de origem aparentemente fundada num critério fonoestético. 
O termo LETRA tem sua origem na tradição gramatical greco-latina, podendo significar tanto um elemento do plano sonoro (que podemos aproximar do fonema) quanto a representação escrita de uma unidade sonora (o grafema). O contexto de emprego do termo eliminaria a imprecisão da metalinguagem (cf. Desbordes 1995: 101) ${ }^{20}$.

Zimmermann (1997: 11) lembra que a descrição fonético-fonológica na lingüística missionária dos séculos XVI e XVII está relacionada à escrita. O alfabeto criado para o tupi antigo e para o quiriri é de base latina, com poucas alterações de acordo com particularidades das línguas. Essas alterações apresentam-se como uso de diacríticos ou de grafemas de pouco uso, como o $\langle\mathrm{y}\rangle$, no alfabeto português, e mesmo propostas como a de Anchieta para a representação da vogal alta central, [ì], por meio de “jota, rubrcrito" (Aryon Rodrigues apontou, em comunicação pessoal, uma influência da gramática grega nessa escolha de Anchieta).

Durante muito tempo, a historiografia lingüística viu ser difundida a idéia de confusão entre oral e escrito, em obras como as que analisamos aqui e também nas gramáticas da Antiguidade clássica (cf. Desbordes 1995: 101-117). Se a metalinguagem nos oferece, de fato, uma imprecisão, é preciso notar que os gramáticos demonstravam ter consciência de quando se referiam ao plano oral e quando se referiam ao plano da escrita.

Mamiani parecia ter clara uma distinção entre os planos sonoro e escrito da língua, ao afirmar que o uso do "accento circumflexo" nos segmentos do tipo Ghŷ representava uma pronunciação branda e aspirada na garganta.

Por outro lado, é preciso considerar que a análise oral presente nas gramáticas aqui em estudo está relacionada ao processo de escrita de línguas sem esta tradição. $\mathrm{O}$ oral era descrito tendo em vista uma escrita que também se iniciava.

Sobre esse aspecto, Swiggers (1997: 156) afirma que a sistematização, a partir do modelo de análise derivado da gramática latina, como a de Manuel Álvares, herdeira de descrições como as de Varrão, Prisciano,

20 "The Stoic philosophers distinguished three aspects of the stoikheion [o elemento sonoro para os gregos]: (a) the sound; (b) the symbol used to represent it; (c) its name. These were translated later into Latin as aspects of litera (letter): potestas, figura, and nomem. Subsequent use of the word litera [letra], or its equivalent in other languages is often ambiguous; sometimes its sense is not far different from that of the modern term 'phoneme"' (Kemp 1995:372). 
Donato e também Quintiliano, caracterizava-se pela segmentação das unidades fônicas reduzidas aos sinais (grafemas) do alfabeto latino, ou seja, não há como separar plano oral do registro escrito.

Em relação aos critérios de descrição e análise dos sons, é possível apontar o uso do critério auditivo como o mais comum nas gramáticas jesuíticas brasileiras do período colonial ${ }^{21}$. $\mathrm{O}$ missionário descrevia a unidade sonora de acordo com a percepção auditiva que ele tinha a partir da realidade observada/percebida.

E ainda que pareção pronunciar, Apábne, \&c. he pella delicadeza com que tocão o i. \& ainda no mermo prerente o exprimem as vezes, vt Apábi.

(Anchieta 1990[1595]:24)

O critério auditivo aparece acompanhado, em várias passagens das gramáticas, de um procedimento que procurava equivalências entre as línguas em descrição com os sistemas português e latino, em sua maioria. A utilização de mais de um critério - auditivo, articulatório e comparativo serviria ao ideal pedagógico das descrições gramaticais jesuíticas. Era preciso utilizar todos os procedimentos e estratégias possíveis, e conhecidos, para executar a contento a missão de ensinar uma língua estrangeira aos missionários.

Se observarmos o trecho de Mamiani que segue, notaremos a descrição realizada com a utilização da busca de equivalências entre as línguas os sons são descritos a partir de comparações com unidades ou agrupamentos sonoros do latim, como na referência a ditongos. O uso do grafema $<æ>$, escrito como no sistema latino, serviria, num alargamento das possibilidades descritivas do uso do alfabeto do latim, para indicar a pronunciação ora como "A fechado", [a], ora como "E largo", próximo à produção de um fone longo, fechado, como [e].

\footnotetext{
21 O uso do critério auditivo é encontrado em toda a tradição clássica ocidental, assim como em trabalhos seguintes até o Renascimento. Destacamos, porém, que em 1586 o dinamarquês Jacob Madsen of Aarhus (1538-86) publica o De Literis, que pode ser considerado como a primeira abordagem de fonética geral no Ocidente. Neste livro há a classificação de unidades sonoras a partir do critério articulatório. Este critério é, de fato, mais utilizado em gramáticas vernaculares européias, como a de Fernão de Oliveira (1536). No âmbito de nossa pesquisa a utilização de abordagens articulatórias é reduzida.
} 
Entre as letras usadas nesta lingua são as seguintes: A, Æ B, C, D, E, G, H, I, Y, K, $\mathrm{M}, \mathrm{N}, \mathrm{O}, \mathrm{P}, \mathrm{R}, \mathrm{S}, \mathrm{T}, \mathrm{V}, \mathrm{W}, \mathrm{Z}$, til. As vogaes entre si não formam diphtongos, mas se pronuncia cada hũa por si como syllaba diversa.

Entre as vogaes se conta aqui o $æ$, ainda que se escreva como diphtongo Latino, para significar hũa vogal entremeya entre o A, \& o E; \& se pronuncia com hũ som diverso das outras vogaes, ou como A fechado que participa do E, ou como E largo que participa do A. v. g.: Inhuræ. Filho. (Mamiani 1877[1699]:1)

\subsection{Partes da oração e casos, palavras e partículas}

É o estudo da PALAVRa que ocupa o maior número de páginas nas artes de gramática do Brasil colonial. Ela é entendida como unidade fundamental na descrição de uma língua, formada por LETRAs e organizada em AJUNTAMENTOS, com outras palavras, resultando em ORAÇÕEs. Os gramáticos mantêm como base de suas descrições a tradição clássica do Ocidente: a descrição das línguas concentra-se em torno das partes do discurso, então chamadas de "partes da oração" - nome, pronome, verbo, particípio, advérbio, preposição, conjunção, interjeição.

Como afirma Swiggers (1997: 9), a gramática clássica ocidental e naturalmente as gramáticas missionárias são organizadas em torno de categorias (e não de processos que afetam formantes dessas categorias). Como resultado dessa abordagem, toma-se a PALAVRA como unidade fundamental, não havendo espaço para análise de unidades significativas menores, como as que chamamos de morfemas. Monzon (1995) aponta, em gramáticas missionárias mexicanas, a existência da percepção do conceito de morfema, ocorrendo com a identificação de partículas portadoras de significado. Tal atitude descritiva também pode ser reconhecida nas gramáticas aqui analisadas, sendo que essa descrição ocorreu a partir da abordagem da formação de palavras e não de análises intrínsecas de unidades menores, como as chamadas partículas.

Raras vezes os gramáticos definiram o que seriam as partes do discurso nas línguas. No nosso corpus tal atitude é verificada, por exemplo, em Figueira, e suas definições para as partes do discurso são baseadas, ou mesmo sendo quase traduções, nas definições de mesmo caráter dadas por Manuel Álvares na sua gramática do latim. 
Substantiuum seu fixum nomen est, quod per se in oratione esse potest, ut dux imperat, miles obtemperat. (Álvares 1832[1572]:105)

Suftantiuos faõ os que podem eftaer na oraçaõ ros por fi com o verbo; vt Abâ omano; hum homem morreo. (Figueira 1621:fl.36-v)

Para a descrição e transmissão didática de aspectos morfológicos, observam-se a utilização de procedimentos como a busca de equivalências com o latim e o português e a explicação dos processos de combinação e formação das palavras. Unidades menores que estas eram chamadas de "partículas" e "artigos". O termo artigo está relacionado a unidades que afixadas em verbos forneciam informações sobre a pessoa gramatical e em nomes indicavam idéia de posse, por exemplo. Partículas, em muitas passagens, correspondem a afixos. É importante ressaltar que a abordagem morfológica é feita com considerações a respeito da organização das palavras em orações, ou seja, aspectos morfológicos e sintáticos são abordados conjuntamente ${ }^{22}$.

\subsubsection{Partes da oração e casos}

Anchieta não fez comentários a respeito de quais seriam as partes da oração que estava descrevendo, mas o tratamento de sua gramática quanto a esse assunto está baseado na tradição gramatical greco-latina, com algumas modificações significativas, como a inclusão da classe dos advérbios nos nomes e a ausência de descrição, separadamente, de classes equivalentes a conjunções e interjeições.

O tratamento de Anchieta, em relação ao que chamamos modernamente de morfologia - termo que só passa a ser utilizado no século XIX -, realiza-se com a constante relação das classes de palavras e os processos de combinação com outras palavras e partículas, transformação (morfofonologia) e concordância/regência das palavras em construções sintáticas, ou seja, também uma morfossintaxe. Tal tratamento conjunto de aspectos

\footnotetext{
22 Swiggers (1997: 120) aponta que a Idade Média apresentou uma importante mudança no ensino universitário da gramática, na qual as categorias morfológicas e as estruturas sintáticas são estudadas juntas, são interligadas, porque toda estrutura de sentido e de formas é interpretada como reflexo de uma realidade apreendida pelo espírito.
} 
morfológicos e sintáticos fica ainda mais evidenciado pela ausência de um capítulo autônomo dedicado à sintaxe, o que o diferencia de Figueira e Mamiani.

O que se observa são artes, voltadas para a transmissão didática de aspectos essenciais das línguas, cuja descrição morfológica, de acordo com a tradição greco-latina ${ }^{23}$, é feita com base na determinação do que seriam as palavras da língua, seus possíveis acidentes, representados por segmentos chamados de partículas, sua organização em paradigmas e a combinação em orações.

A palavra era descrita, morfologicamente, em termos da existência, ou não, de alterações nas formas e também pelo acréscimo, ou não, de segmentos (partículas, artigos)

Os verbos simplices desta lingua são todos os monosyllabos: \& se houvesse quem podesse perfeitamente alcançar a força de todos os vocabulos, tenho para mim que acharia que toda a lingua consiste em vocabulos monosyllabos, que servem de raizes para formar os compostos... (Mamiani 1877[1699]:68)

a partir de seu significado (critérios semânticos)

[Sobre a posposição çocê] Esta significa, lugar, \& excerro, vt, Itâçocê, lapidem ruper, vel plurquam lapis ... (Anchieta 1990[1595]:108)

e também tendo em vista as relações que estabeleciam nas estruturas sintáticas

Os Adverbios desta lingua se dividem em quatro classes. A primeira he dos Adverbios, que se costumão pôr no principio da oração. A segunda he dos Adverbios, que se usam no fim dos Nomes, \& verbos, com os quaes fazem composição. A terceira he dos Adverbios, que se costumão pôr depois de alguma palavra da oração. A quarta he dos Adverbios indifferentes. (Mamiani 1877[1699]:87).

23 "A teoria gramatical clássica estabeleceu a palavra como unidade operacional básica. A morfologia e a sintaxe tradicionais foram construídas sobre esse alicerce. A morfologia estudava a estrutura interna da palavra e a sintaxe a combinatória dos vocábulos em orações, desde os gregos e os latinos." (Biderman 2001:105) 
Em relação à abordagem de casos, os gramáticos reconheceram que o tupi antigo e o quiriri não apresentavam declinações indicadoras de caso, tal como no latim e no grego. No entanto, a nomenclatura dos casos latinos é extensivamente utilizada para a explicação da função que as partes da oração das línguas exerciam. A partir dos casos latinos, seriam abordadas, num procedimento que privilegiava a transmissão didática, as funções das categorias gramaticais próprias das línguas indígenas. $\mathrm{O}$ tratamento das "preposições" 24 era fundamental nessa perspectiva, uma vez que seriam elas, segundo os gramáticos, as unidades responsáveis, em algumas construções, pelo estabelecimento de equivalências com os casos latinos.

Figueira, por exemplo, descreveu a maneira pela qual cada caso se expressaria em tupi antigo ${ }^{25}$. Ele indicou, por critérios funcionais, baseados na co-ocorrência de itens lexicais numa estrutura sintática, como as unidades da língua indígena se assemelhariam aos casos latinos. Se Figueira reconheceu ausência de marcas formais para indicar casos, ele descreveu o que poderia ser a manifestação desses casos no tupi antigo, como também fez Mamiani para o quiriri.

Os nomes nesta lingua, cõmummente, não tem distinçaõ de numeros, singular, \& plurar; nem tambem de casos; mas a mesma voz serue de ambos os numeros, \& em todos os casos. v.g. Oca, casa, ou casas: Apyaba, homẽ, ou homẽs.

E os casos se conhecem por algũas preposiçoês, ou modos de collocar os nomes entre si; ou tambem com os verbos.

(Figueira 1621:fl.2-v)

Os “casos dos nomes” em Figueira são explicados a partir da descrição da ordem de colocação dos termos em sintagmas ou pela indicação das unidades responsáveis pela transmissão da idéia desejada, as chamadas preposições.

\footnotetext{
24 Nenhum dos gramáticos aqui analisados abandonaram a metalinguagem latina para a classificação de segmentos pospostos a outros nas línguas que descreviam. Mesmo reconhecendo como pospostos segmentos que estavam sendo descritos, eles continuaram com a utilização do termo preposição. Na tradição da gramática missionária, Antonio Ruiz de Montoya (1585-1652), gramático do guarani, destaca-se, ao chamar as posposições guaranis de posposiç̃̃es, abandonando o termo corrente baseado na gramática latina (cf. D. Rodrigues 1997).

25 O tupi antigo, segundo Rodrigues (1997: 381), apresentava, de fato, casos, como os locativos pontual e difuso e o caso predicativo. Anchieta aponta em sua gramática (p.37, edição fac-similar de 1990) a existência de um caso vocativo.
} 
Mamiani descreveu casos do quiriri, dizendo que estes poderiam ser reconhecidos pela sua colocação na oração (nominativo e genitivo) ou pelo uso de "preposições" (os outros casos): "porque nesta lingua não ha caso algum sem preposiz̧ão fóra do Nominativo, E genitivo...” (p. 6). Ressaltou também que não seria possível falar em declinações indicadoras de casos, como no latim, mas reconheceu os casos pelo sentido e função estabelecidos pelas unidades na construção sintática, um critério semântico-funcional.

A diversidade destes artigos [prefixos] he o fundamento de dividirmos os nomes, \& verbos em diversas Declinações: \& porque os mesmos artigos servem assim aos nomes, como aos verbos, a mesma divisão serve de regra commũ a huns, \& a outros.

Chamo Declinações, não porque sejam declinações dos casos nos nomes, ou de tempos, \& modos nos verbos, mas porque são quasi declinações dos pronomes, ou possessivos, ou substantivos, compostos com os mesmos nomes, \& verbos pelas tres pessoas em ambos os numeros, singular, \& plural: \& pela mesma razão, \& por ser regra geral que abraça tãbem os verbos, se poem juntas as declinações dos nomes com as dos verbos. (Mamiani 1877[1699]:10)

\subsection{A sintaxe nas artes de gramática}

A abordagem da sintaxe em artes de gramática jesuíticas é algo que deve ser examinado com atenção, uma vez que está extremamente relacionada à morfologia e não ocupa um número extenso de páginas, sendo, inclusive, ausente como parte autônoma da gramática de Anchieta.

Em primeiro lugar, é importante lembrar que a tradição gramatical da Antiguidade clássica e as gramáticas modelares do Renascimento (obras de Manuel Álvares e Nebrija, para a tradição jesuítica) também se caracterizaram por não apresentar uma ampla descrição de fatos sintáticos. Podese dizer, assim, que essa tradição gramatical concentrou-se mais nas questões que diziam respeito às partes do discurso.

As abordagens sintáticas, em obras da tradição clássica ocidental, tinham por base o estudo da palavra em situação de discurso, sendo que a concepção latina de discurso é uma concepção morfológica (Kristeva 1980:196). Ou seja, há uma sintaxe organizada em torno da palavra, das relações estabelecidas pelo nome e pelo verbo, com atenção para os fenômenos de concordância das classes nominais com os verbos, e também para a regência, em que os complementos que eram pedidos por palavras em determinadas construções eram apontados. 
É esse o tipo de estudo sintático, com a descrição da construção das frases (ordem dos elementos), apresentado nas artes jesuíticas, não havendo destaque para uma descrição extensa a respeito das funções que as palavras exerciam na oração, como sujeito e complemento.

O escasso tratamento dos fenômenos sintáticos pode estar ligado a alguns fatores, como: a herança da Antiguidade clássica, que de fato se dedicou mais ao estudo da palavra, sem uma extensa abordagem da combinação de unidades maiores que sílabas ou nomes compostos (cf. Swiggers 1997, capítulo I); as características das línguas faladas no Brasil colonial (a diversidade do estabelecimento das relações morfossintáticas pode ter levado ao julgamento de que essas línguas não teriam sintaxe ou apresentariam, mesmo assim, uma sintaxe pobre); o fato de que era a lógica que se dedicava a alguns estudos que hoje entendemos como sintáticos.

Dessa maneira, a sintaxe observada nas gramáticas dos jesuítas é um conjunto de regras relativas às classes de palavras, a partir do momento em que elas se integram num discurso. $\mathrm{O}$ que deve ser registrado com destaque é o fato de que não se pode falar em uma separação rígida entre morfologia e sintaxe.

\subsubsection{As descrições do nível sintático da línguas}

Figueira inicia sua "sintaxa ou construição das partes da oração" com a afirmação de que a estrutura sintática do tupi antigo seria simples, por não ter casos nem declinações.

Como nesta lingua não ha variedade de caros, nem de generos, mais que o que re tem virto, fica facil a combinação dos verbos com os nomes, como fe verâ. (Figueira 1621: fl.81-v)

O critério de análise dos aspectos sintáticos levava em conta a ordem de colocação dos elementos na oração e quais elementos eram pedidos por outros.

O vro enrinara a boa collocaçaõ das partes da oração entre ri, mas appontemos aqui algũas que pedem certos lugares, arri como vemos no latim, que erta preporiçã̃ Tenus, rempre re põe depois do nome que rege \& reria erro intolerauel mudarlhe o ritio, pondoa antes do nome como as outras. (Figueira 1621: fl. [90]60) 
Se Anchieta não propôs uma parte autônoma para o estudo da sintaxe, é possível, mesmo assim, verificar o tratamento conjunto de aspectos morfológicos e sintáticos em sua gramática. Observe-se, por exemplo, o uso do termo suposto, equivalente à idéia de nominativo.

Do Reciproco, O, que he, re, ruus, a, um, re vra rimpliciter quando re refere a oração á perroa agente como na lingua latina, vt.

Pedro ojucâ ogúba, Petrus occidit ruum patrem.

Nertas orações rimples não ha duuida.

Auendo dous verbos nũa oração, q[ue] fazẽ como duas orações dependentes hũa da outra, rempre re ha de ter rerpeito ao principal verbo da oração, \& ao rupporto delle re ha de referir ao reciproco ... (Anchieta 1990[1595]:53-54)

Podemos verificar também que, ainda não sendo objeto de estudo principal da sintaxe nas gramáticas missionárias, a abordagem de fenômenos sintáticos a partir dos papéis desempenhados pelas unidades esteve presente em Anchieta e Mamiani.

Tambẽ podẽ ter significação parsiua, raltẽ na quelles cuja acção renão pode fazer pella perroa agente vt aû. eu como Ayeû, eu me como. (Anchieta 1990[1595]:91, grifo meu)

Os compostos com, mo, \& ro, differem nirto que nos comportos com, mo, não participa a perfoa agente do que re fas, vt, agebîr torno, amogebîr, faço o tornar não tornando eu. (Anchieta 1990[1595]:118, grifo meu)

Se o relativo fôr agente assim do verbo Neutro como do Passivo, se faz participio activo em Ri assim de hum como de outro verbo. v.g. Deos, que me ama a mim: Tupã ducari hidiohò. Pedro, que matou ao seu inimigo: Però dupari dumará.

Se o Relativo fôr nominativo paciente do verbo passivo, se faz Participio em Ri, ou em Te. v.g. Pedro, a quem matey: Però dipacriri hinhà ou Sipacritè hinhá. (Mamiani 1877[1699]:55, grifos meus)

Quando houve referências às funções das partes do discurso numa oração foi porque estas condicionavam alterações nas formas das palavras, indicadas pelos gramáticos a partir da descrição das partículas que alteravam unidades e/ou segmentos. $O$ estudo da sintaxe como descrição de funções como sujeito/predicado era parte dos estudos da lógica, assim como essa metalinguagem, e, portanto, não merecia extensa abordagem, ainda 
mais em obras como as artes de gramática, que prezavam pela brevidade da exposição. Mamiani indicou, no trecho que segue, a utilização dos termos sujeito/predicado nos estudos da lógica.

Tres são os significados do Verbo Sum, a saber: Ser, Estar, Ter. Para o primeiro significado de Ser, serve o mesmo nome ou Adjectivo ou Substantivo, que costuma ser o segundo Nominativo do Verbo Ser, \& dos Logicos se chama Predicado, \& este se poem em primeiro lugar antes do primeiro nominativo, a que os Logicos chamão Sogeito. (Mamiani 1877[1699]: 65, grifo meu)

A diversidade, em relação ao português, da ordem dos elementos na oração também foi registrada por Figueira e Mamiani. O tupi antigo e o quiriri poderiam apresentar a ordem Verbo-Nominativo.

Primeiramente o nome, ou pronome em respeito do verbo podem eftar antes ou derpois. vt Oço Pedro; Pedro oço. Yxe aico: Aico yxe. (Figueira 1621:60b)

Da Syntaxe de todas as Partes da Oração entre si.

De ordinario nesta lingua precede o verbo ao Nominativo.

(Mamiani 1877[1699]:98)

\section{Conclusões}

Procuramos ressaltar o que de mais comum pode ser verificado na produção gramatical jesuítica brasileira dos séculos XVI e XVII sobre as línguas indígenas. Sem dúvida, o que houve de comum nas descrições gramaticais foi também o que a gramaticografia da época renascentista utilizou com mais destaque, como, por exemplo, o método que privilegiava a busca de equivalências entre a língua que estava sendo descrita e línguas de grande prestígio, como o latim. Apontamos também a utilização de uma metalinguagem que acabaria por caracterizar toda a produção gramatical do Ocidente. Encontramos nas artes dos jesuítas a indicação de que uma redução da língua a regras deveria ser breve e econômica. O que de fato contribui para a classificação das obras jesuíticas como artes de gramática, termo que por si só indica uma descrição breve de aspectos gramaticais essenciais. Mas, se podemos traçar uma linha comum em relação às descrições dos jesuítas, podemos também apontar alguns aspectos importantes que os diferenciaram. 
José de Anchieta é o autor que propôs algumas soluções descritivas que podem ser apontadas como originais, em relação a termos utilizados e a propostas de descrição de aspectos particulares do tupi antigo. De fato, o que se pode apontar de comum em relação a Anchieta e aos outros jesuítas deve ser relacionado ao fato de que o primeiro gramático de uma língua brasileira foi, também, a matriz de uma tradição de descrição de línguas.

Se a lingüística indígena aponta positivamente aspectos da gramática anchietana (cf. trabalhos de Navarro e Rodrigues), que de fato auxiliou muito numa reconstrução do tupi antigo no âmbito de pesquisas de lingüística histórica e lingüística indígena, a historiografia não pode deixar de apontar que foram também algumas dessas características (como a estrutura da gramática e a extensa abordagem de fenômenos morfofonológicos, ao lado do intenso uso de metalinguagem e exemplos em latim) as responsáveis pela classificação da gramática de Anchieta como difícil e complicada para uma primeira aprendizagem da língua ${ }^{26}$, ocasionando, inclusive, a necessidade de uma arte mais didática, o que viria a ser alcançado com a obra de Figueira, 26 anos depois.

Luís Vincencio Mamiani também se destaca por um aspecto particular de sua gramática. Ele foi o único a fazer comentários a respeito dos procedimentos e estratégias de descrição utilizados, além de apontar também o que considerava como o caminho ideal de aprendizagem.

Já Luís Figueira funciona como uma síntese do que era o trabalho gramatical dos missionários. Se não há originalidades a apontar, Figueira foi, sem dúvida, um exemplar de sua época, no sentido de que sua obra pode ser apontada como um modelo do que a Companhia de Jesus deveria entender como a gramaticografia de uma língua chamada de exótica. As duas edições, ainda no século XVII, evidenciam a boa aceitação de sua gramática.

Se há diferenças, há também muitas semelhanças. E são essas que nos autorizam a efetuar um recorte na historiografia da lingüística brasileira aqui denominado de lingüistica missionária jesuítica, e que apresenta a produção de gramáticas de maneira semelhante e com o mesmo objetivo.

Recebido em setembro de 2002 Aprovado em setembro de 2004

\footnotetext{
26 Manuel Cardoso na apresentação à primeira edição da gramática de Figueira, possivelmente em 1621, apresenta esses comentários em relação à descrição de Anchieta.
} 


\section{REFERÊNCIAS BibliográFiCAS}

Altman, Cristina. 1997. As gramáticas das 'línguas gerais' sul-americanas como um capítulo da Historiografia Lingüística Ocidental. Actas del I Congreso Internacional de la Sociedad Española de Historiografia Lingüística. Separata. Ed. por Mauro F. Rodríguez, Francisco G.Gondar e Nancy V. Veiga. Coruña, 18-21 de fevereiro de 1997.

1999. From 'Insula Vera Crux' to 'Terra Brasiliensis'. History, (Hi)Stories and Historiography of Brazilian Linguistics. History of Linguistics 1996. Vol. 2: From Classical to Contemporary Linguistics. Offprint. Ed. por David Cram, Andrew Linn e Elke Nowak. Amsterdam \& Phliadelphia: John Benjamins.

2000. As 'línguas gerais' e a empresa missionária colonial. Linguagem e representação metalingüística. MS.

Álvares, Manuel. 1832[1572]. Institutio Grammatica. Roma: Soc. Jesu. (1 $1^{\text {a }}$. ed com publicação em Lisboa por Joam da Barreira.)

Anchieta, José de. 1990[1595]. Arte de gramática da língua mais usada na costa do Brasil. Fac-similar da 1.ed. Apres. de Carlos Drumond. Adit. do Pe. Armando Cardoso. São Paulo: Edições Loyola. (1 ${ }^{a}$. ed. 1595. Coimbra: Antonio Mariz; $2^{\mathrm{a}}$. ed. 1874, Leipzig: Julio Platzmann; $3^{\mathrm{a}}$. ed. 1876, idem; $4^{\text {a }}$ ed. 1933, R. de Janeiro: Bibl. Nac. do R. de Janeiro; $5^{a}$. ed. 1946, São Paulo: Ed. Anchieta; 6 ${ }^{a}$. ed. 1980, Salvador: UFBA.) Auroux, Sylvain. 1992. A revolução tecnológica da gramatização. Campinas: Unicamp.

Batista, Ronaldo de O. 2002. As linguas difficultosas e os linguas peritos. Artes de gramática jesuíticas no Brasil colonial dos séculos XVI e XVII. Dissertação de Mestrado, FFLCH/USP.

Biderman, Maria Teresa C. 2001. Teoria Lingüística. São Paulo: Martins Fontes. ( $1^{\text {a }}$. ed. publicada em 1978, com o título Teoria Lexical e lingüistica computacional, São Paulo: LTC.)

Desbordes, François. 1995. As concepções sobre a escrita na Roma antiga. [Trad. de Fulvia Moretto e Guacira Machado do orig. francês Idées romaines sur l'écriture, 1990.] São Paulo: Ática.

Drumond, Carlos. 1990. Prefácio à nona edição da Arte de gramática da lingua mais usada na costa do Brasil. São Paulo: Edições Loyola.

Figueira, Luís. 1621(?). Arte da Lingva Brasilica. Lisboa: Manoel da Silva. (2a. ed. 1687, Arte de grammatica da Lingua Brasílica, Lisboa: Miguel Deslandes; $3^{a}$. ed. 1795, Arte da Grammatica da Lingua do Brasil, Lisboa: Officina Patriarcal.) 
Kemp, J.A. 1995. Phonetics: Precursors to Modern Approaches. Koerner, E.F.K. \& R.E. Asher (eds.). 1995. Concise History of the Language Sciences: From the Sumerians to the Cognitivists. Oxford \& New York: Pergamon: 371-388.

Koerner, E.F. Konrad. 1989a. On the problem of 'influence' in Linguistic Historiography. Practicing Linguistic Historiography: Selected Essays, 3146. Amsterdam \& Philadelphia: John Benjamins. 1989b. Models in Linguistic Historiography. Practicing Linguistic Historiography: Selected Essays, 47-60. Amsterdam \& Philadelphia: John Benjamins.

1996a. Questões que persistem em Historiografia da Lingüística. [Trad. de Cristina Altman do orig. inglês "Persistent Issues in Linguistic Historiography”. Linguistic Historiography. Amsterdam \& Philadelphia: John Benjamins, 1995.] ANPOLL. Revista da Associação Nacional de Pós-Graduação em Letras e Lingüística 2: 45-70.

1996b. A questão da metalinguagem na Historiografia da Lingüística. [Trad. de Cristina Altman do orig. inglês "Metalanguage in Linguistic Historiography". Professing Linguistic Historiography. Amsterdam \& Philadelphia: John Benjamins, 1995.] DELTA 12: 1.95-124.

Kristeva, Julia. 1980. História da linguagem. [Trad. de Maria Margarida Barahona do original francês Le Langage, cet inconnu, 1969.] Lisboa: Edições 70.

Law, Vivien. 2003. The history of linguistics in Europe. Cambridge: Cambridge University Press.

Mamiani, Luís Vincencio. 1877[1699]. Arte de Grammatica da Lingua Brasilica da Naçam Kiriri. Rio de Janeiro: Biblioteca Nacional. (1ª. ed., Lisboa: Miguel Deslandes.)

Montoya, Antonio Ruiz de. 1994[1640]. Arte, y bocabulario de la lengua guarani. Rep. fac-similada da $1^{\mathrm{a}}$. ed. Madrid: Cultura Hispânica.

Monzon, Cristina. 1995. La morfología en las primeras Artes de las lenguas amerindias. Ameríndia 19/20: 253-261.

Navarro, Eduardo. 1995. Problemática lingüística do Renascimento às missões e as gramáticas da língua tupi de José de Anchieta e Luiz Figueira. Tese de Doutorado. FFLCH/USP, São Paulo.

Nebruja, Antonio de. 1946[1492]. Gramatica Castellana. Madrid: Ed. Junta del Centenario.

Padley, G.A. 1976. Grammatical theory in Western Europe - 1500-1700. Cambridge: Cambridge University Press. 
Robins, R.H. 1979. Pequena História da Lingüística. [Trad. de Luiz M.M. de Barros do orig. inglês A Short History of Linguistics, 1967.] Rio de Janeiro: Ao Livro Técnico.

Rodrigues, Aryon D. 1993. Línguas Indígenas: 500 anos de descobertas e perdas. DELTA. 9:1.83-103.

1994. Linguas Brasileiras. Para o conbecimento das línguas indígenas. $2^{a}$. edição. São Paulo: Edições Loyola.

1997. Descripción del tupinambá en el período colonial: el Arte de José de Anchieta. Zimmermann (ed.).

1998. O conceito de Língua Indígena no Brasil, I: os Primeiros Cem anos (1550-1650) na Costa Leste. Linguas e Instrumentos Lingüísticos 1.59-78. Campinas: Ed. Pontes.

Rodrigues, Danielle. 1997. La obra lingüística de Antonio Ruiz de Montoya. Zimmermann (ed.).

RosA, Maria Carlota. 1992. Descrições missionárias de língua geral nos séculos XVI-XVII: que descreveram? Papia 2:1: 85-98.

1995. Acerca das duas primeiras descrições missionárias de Língua Geral. Ameríndia 19/20: 273-284.

1997. As línguas bárbaras e peregrinas do Novo Mundo segundo os gramáticos jesuítas: uma concepção de universalidade no estudo de línguas estrangeiras. Revista de Estudos da Linguagem 6:2: 97-149.

Swiggers, Pierre. 1979. Note épistémologique sur le statut de l'historiographie de la linguistique. Histoire, Epistémologie, Langage 1:1:61-63.

1981. The history writing of Linguistics: a methodological note. General Linguistics 21:1:11-16.

1983. La méthodologie de l'historiographie de la Linguistique. FLH 4: 55-79.

1997. Histoire de la pensée linguistique. Analyse du langage et réflexion linguistique dans la culture occidentale, de l'Antiquité au XIXe. siècle. Paris: PUF.

Zimmermann, Klaus. (ed.). 1997. La descripción de las lenguas amerindias en la época colonial. Frankfurt am Main: Vervuert; Madrid: Iberoamericana. 